headache be produced. As you have a sort of vested right in chloroform, I know you will be interested in my observations, and you are at liberty to publish them if you think them worthy.-Very sincerely yours,

\title{
F. Churchill.
}

\section{Article VIII.-Case of Tuming, instead of Craniotomy, in a} Contracted Pelvis. By John Traill, Esq., Surgeon.

MrS R_, rather undersized, but otherwise apparently well-formed, was confined of her first child in May 1836-being then in her twenty-sixth year. Her labour from the commencement, was tedious, notwithstanding the employment of bleeding, tartar emetic, etc.; and after two days' duration, she was attacked with violent convulsions, which were overcome only by profuse bleeding, and were followed by complete coma.

In this state, the head being still at the brim of the pelvis, she was, with great difficulty, and after much delay, delivered by the forceps-the child having evidently been dead for some time. The recovery was imperfect and protracted.

Her second confinement took place in June 1838. It was again most difficult and protracted; and after two days' continuance, resulted in convulsions followed by stupor, which continued for more than a week. She was again, with even more difficulty than formerly, and after several hours' exertion, delivered of a dead child by the forceps - after we had all but decided on having recourse to craniotomy, which, indeed, had this case occurred some years later in my practice, I should, without hesitation, have performed at an earlier period of the labour, and which, in subsequently reflecting on the case, I have often blamed myself for so long delaying.

In both labours I had the advice and assistance of Dr Bruce and of my brother, Mr W. Traill.

The patient remained for several weeks in a dangerous state, and her recovery was so slow, that she was unable to leave her bed for several months afterwards. She never regained her usual health, constantly suffering from irregular and scanty menstruation, with violent headache, and determination to the head.

At this time I had decided, in the event of pregnancy again taking place, to recommend the induction of premature labour.

Some months ago, Mrs R-, now in her forty-third year, informed me that she was again pregnant, and that she expected to be confined about the end of May.

Having carefully studied Professor Simpson's papers on "Turning as a substitute for Craniotomy," and believing it to be a favourable and proper case for the plan proposed, I decided on allowing labour to go on to the full time. 
May 19.-This morning I was called to Mrs R-, and was greatly annoyed to find her in a most unfavourable state. The membranes had given way six days previously, and the liquor amnii had since been constantly dribbling off; moreover, she had had smart labourpains for thirty-six hours, and was in a complete state of mental prostration and hopelessness as to the result, both to herself and the infant-so much so, that the child's dead clothes were provided, and she protested against my being sent for, declaring that she had no chance of being delivered for days to come. On examination, I found the head firmly impacted at the brim of the pelvis, but only a small part within reach of the finger elongated, and the scalp swollen; the os uteri, about the size of a crown piece, not acted on by the pains but quite dilatable; the contraction at the brim of the pelvis was greater than I had calculated on-the sacro-pubic diameter did not appear to me to exceed three inches.

Having decided on still attempting to turn, I gave chloroform to the full extent, and then with some difficulty succeeded in pushing up the head and passing the hand into the uterus. I found the liquor amnii almost entirely evacuated, and the uterus closely enfolding the infant; the pulsation in the cord was weak; and while searching for a foot, the child had repeated convulsive movements. This induced me to hurry the operation as much as possible, but I found considerable difficulty in bringing the head through the brim, so that fully half an hour elapsed before delivery could be completed. The child, a male rather under the average size, was quite still for several minutes, but ultimately recovered.

When the mother awoke from her sleep and heard the cries of her infant, she would not be convinced but that we were deceiving her, both as to her own delivery and as to the possibility of having given birth to a living child. She has made a rapid and excellent recovery without one untoward symptom, and now, in better health than she has enjoyed for eighteen years, is suckling her child, a strong, healthy boy.

The gratifying result of this case has very strongly impressed on my mind the soundness of the principles on which Professor Simpson has advocated his proposals as to the practice of turning in contracted pelvis, and has led me to believe that the facility afforded to the advance of the head through the brim of the pelvis in consequence of its changed position, and of the traction which we are enabled to exert through the extruded body of the child, is much greater than could at the first view be considered possible.

If I had been aware of the degree of contraction existing, I do not think I would have ventured to have allowed labour to go on to the full period. The head was of average size, or very nearly so; - the sacro-pubic diameter, I am certain, did not exceed three inches (I believe it to have been considerably less); but be that as it may, I found the head firmly wedged, and yet only just entered within the brim, after thirty-six hours of continued smart uterine 
action, whilst the state of the child's circulation and nervous system, as ascertained by the hand in utero, showed that its life could not have been much longer protracted.

I cannot therefore doubt, that by the practice pursued, the life of the child was saved; nor do I think that the benefits resulting to the mother can be considered less important.

From the degree of deformity of the pelvis, the firm impaction of the head, and its non-advancement-notwithstanding the prolonged uterine action-I do not believe that delivery by the long forceps would have been possible. I believe that craniotomy must ultimately have been resorted to ; followed as in the two previous labourswhich occurred under circumstances in every way more favourable -by at best a tedious, protracted and imperfect recovery.

Arbroath, July 16, 1853.

\section{3มart Secrir.}

\section{REVIEWS.}

Illustrazione di tutti gli Strumenti Chimurgici scavati in Ercolano e in Pompei e che ora conservansi nel Real Museo Borbonico di Napoli. Compresa in Sette Memorie lette all' Academia Ercolanese. Dal Cavaliere Benedetto Vulpes, Professore di ClinicaMedica nell' Università di Napoli. Napoli : 1847. 4to. Pp. 94.

Description of all the Surgical Instruments excavated at Herculaneum. and Pompeii, and presently preserved in the Royal Bourbon Museum of Naples. Comprised in Seven Memoirs read to the Herculanean Academy. By Benedetto Vulpes, Cavalier, etc. etc. Naples: 1847.-(Continued from $p .546$ of previous volume.)

We now direct attention to the fifth memoir in Professor Vulpes' work, in which the first instruments described are the pincers or forceps (the pinzette or mollétte of the Italians, the vulsella of

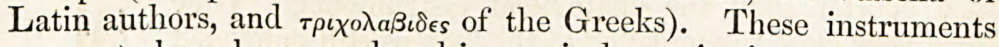
appear to have been employed in surgical practice in very much the same way as the common dressing forceps are now. Special reference, however, is made to their employment in the treatment of wounds, ulcers and fistulas, for the purpose of introducing medicated preparations into situations where the fingers of the surgeon could not reach. The pincers were originally found in the excavations at Herculaneum and shortly afterwards at Pompeii. In number they amount to eighty-eight. Of these, fifteen are named anatomical, one 